\title{
POSTINJECTION DELIRIUM/SEDATION SYNDROME (PDSS) FOLLOWING OLANZAPINE LONG-ACTING INJECTION: A CASE REPORT
}

\author{
Lovro Uglešic ${ }^{1}$, Trpimir Glavina ${ }^{2}$, Davor Lasić ${ }^{2}$ \& Mariano Kaliterna ${ }^{1}$ \\ ${ }^{l}$ Department of Psychiatry, University Hospital Centre Split, Split, Croatia \\ ${ }^{2}$ Department of Psychiatry, University of Split, School of Medicine, Split, Croatia
}

received: 16.9.2016;

revised: 20.12.2016;

accepted: 18.1 .2017

\section{INTRODUCTION}

The introduction of long-acting injectable antipsychotics has provided more efficient treatment of many patients with schizophrenia, especially those with poor therapeutic compliance (Leucht et al. 2011, Jakovljević 2014). Postinjection delirium/sedation syndrome (PDSS) following olanzapine long-acting injection (LAI) is a serious adverse event, which includes symptoms of sedation (ranging from mild in severity to excessive, i.e. coma) and/or delirium (including confusion, disorientation, agitation, anxiety and other cognitive impairment) (Detke et al. 2010). The syndrome is believed to be caused by an olanzapine overdose due to unintended, prompt input/entry of a larger amount of drug in the bloodstream, whereas the treatment is conservative (McDonnell et al. 2010).

PDSS following olanzapine LAI occures in approximately $0.07 \%$ of injections or $1.4 \%$ of patients (Kane et al. 2010). Interestingly, since introduction of olanzapine LAI into our department (February of 2012), we administered approximately 4000 injections and had only one case of PDSS ( $0.025 \%$ of injections), which we now present.

\section{CASE REPORT}

MG, a 55-year old male, was admitted to the Department of psychiatry for the first time in May of 2011, because of acute psychotic reaction. In February of 2012, after a months-long period of poor therapeutic compliance, patient was admitted to our department for a second time, again because of the acute psychotic reaction. Olanzapine LAI (a $405 \mathrm{mg}$, given every 4 weeks) was introduced for the first time. During the next 10 months patient was in good remission and had excellent adherence.

In January of 2013, ten minutes after the application of regularly scheduled olanzapine LAI, which was at that time patients only medication, he suddenly became somnolent and psychomotorically slowed, with stable cardiorespiratory parameters (AP 110/85 $\mathrm{mmHg}$, HR $90 \mathrm{bpm}$ ) and normoglycemia (BGL 5.8 $\mathrm{mmol} / \mathrm{L}$ ). Then, in next 15-20 minutes, he gradually became stuporous, while cardiorespiratory parameters were still stable (ECG was normal; blood gases values were in normal limits). Multiple intravenous infusions of isotonic crystalloid solutions were administered, along with the continued monitoring of patient in Intensive care unit. At day 2, after approximately 32 hours from application of injection, patients consciousness gradually started to normalize. At day 3 he was still conscious, but slightly confused in contact and psychomotorically slowed. At day 4 he was conscious, alert, with all psychical functions intacted. Routine blood tests were made two times, and these parameters were out of range: (day 3) CRP $52.6 \mathrm{mg} / \mathrm{L}$, ALT $62 \mathrm{IU} / \mathrm{L}$; (day 6) CRP $12.2 \mathrm{mg} / \mathrm{L}$, lactates 2.7 $\mathrm{mmol} / \mathrm{L}, \mathrm{ALT} 65 \mathrm{IU} / \mathrm{L}$. At day 8 patient was released from the Department.

\section{DISCUSSION}

The potential for onset of PDSS is greatest within the first hour after injection, and all patients fully recover within 72 hours (Detke et al. 2010). Although the symptoms are, generally, consistent with olanzapine overdose (Kane et al. 2010), and higher-thanexpected systemic olanzapine concentrations have been observed, the exact mechanism of PDSS is unknown (McDonnell et al. 2010). Certainly, it most likely involves accidental entry of the medication into the bloodstream following blood vessel injury during the injection process (Detke et al. 2010). A great similarity in incidence of olanzapine LAI PDSS to that of Hoigne's syndrome (post-injection syndrome following accidental intravascular injection of penicillin procaine $\mathrm{G}$; ocurres in $0.08 \%$ of injections) (Downham et al. 1978) suggests that these findings may be approximating the naturally occurring background rate for accidental direct or indirect intravascular injection during any intramuscular injection process (Detke et al. 2010).

However, the type and intensity of clinical presentation that might occur would depend on the formulation and inherent safety profile of the medication 
being injected. For risperidone LAI, for example, rare cases of an embolic-type reaction have been reported with the microsphere formulation (Tang \& Weiter 2007). On the contrary, for haloperidol decanoate and other oil-based typical antipsychotic LAI, no specific instances of inadvertent intravascular injection can be found in the literature (Detke et al. 2010). However, olanzapine LAI, as a salt-based formulation, may carry risk for a post-injection syndrome as a result of the greater solubility of the salt in blood than in muscle tissue (McDonell et al. 2010, Noyes \& Whitney 1987). Moreover, because of the specific adverse-event profile that accompanies the olanzapine molecule, excessive amounts of olanzapine entering the blood stream can result in noticeable symptoms consistent with olanzapine intoxication, particularly excessive sedation and/or delirium (Detke et al. 2010).

There were indications that lower BMI and/or higher age, poorer general health and haemorraghic diathesis increase the predisposition for occurrence of PDSS. However, none of these hypotheses have been able to be confirmed (Detke et al. 2010). Lastly, we believe that PDSS should be recognised as a new entity in emergency psychiatry (Buts \& Van Hecke 2014).

\section{Acknowledgements: None.}

Conflict of interest: None to declare.

\section{Contribution of individual authors:}

Lovro Uglešić was involved with conception and design, manuscript preparation, data collection, literature searches and writing the paper.

Trpimir Glavina was involved in manuscript preparation, patient's care, data collection and interpretion of data.

Davor Lasić was involved in manuscript preparation, writing the paper and reviewed draft manuscript.

Mariano Kaliterna was involved with writing the paper and literature searches.

\section{CONCLUSION}

In summary, this case emphasizes the requirement for a heightened awareness about the risk of PDSS in patients receiving olanzapine LAI. Further research is needed to fully clarify the pathophysiology of PDSS and to explore the possibility of specific risk factors.

\section{References}

1. Buts K, Van Hecke J: Post-injection delirium/sedation syndrome following injection of olanzapine pamoate: a new syndrome in emergency psychiatry. Tijdschr Psychiatr 2014; 56:273-6.

2. Detke HC, McDonnell DP, Brunner E, Zhao F, Sorsaburu S, Stefaniak VJ, Corya SA: Post-injection delirium/sedation syndrome in patients with schizophrenia treated with olanzapine long-acting injection, I: analysis of cases. BMC Psychiatry 2010; 10:43.

3. Downham TF, Cawley RA, Salley SO, Dal Santo G: Systemic toxic reactions to Procaine Penicillin G. Sex Transm Dis 1978; 5:4-9.

4. Jakovljević M: Long-acting injectable (depot) antipsychotics and changing treatment philosophy: Possible contribution to integrative care and personal recovery of schizophrenia. Psychiatria Danubina 2014; 26:304-307.

5. Kane JM, Detke HC, Naber D, Sethuraman G, Lin DY, Bergstrom RF, McDonnell DP: Olanzapine long-acting injection: a 24-week, randomized, double-blind trial of maintenance treatment in patients with schizophrenia. Am J Psychiatry 2010; 167:181-189.

6. Leucht C, Heres S, Kane JM, Kissling W, Davis JM, Leucht S: Oral versus depot antipsychotic drugs for schizophrenia - A critical systematic review and metaanalysis of randomised long-term trials. Schizophrenia Research 2011; 127:83-92.

7. McDonnell DP, Detke HC, Bergstrom RF, Kothare P, Johnson J, Stickelmeyer M, Sorsaburu S, Watson SB, Mitchell MI: Post-injection delirium/sedation syndrome in patients with schizophrenia treated with olanzapine longacting injection, II: investigations of mechanism. BMC Psychiatry 2010; 10:45.

8. Noyes AA, Whitney WR: The rate of solution of solid substances in their own solutions. J Am Chem Soc 1987; 19:930-934.

9. Tang J, Weiter JJ: Branch retinal artery occlusion after injection of a long-acting risperidone preparation. Ann Intern Med 2007; 147:283-284.

\section{Correspondence:}

Lovro Uglešić, $M D, P h D$

Department of Psychiatry, University Hospital Centre Split

Spinčićeva 1, 21000 Split, Croatia

E-mail:lovro.uglesic@gmail.com 